\title{
New thyreophoran dinosaur material from the Early Jurassic of northeastern Germany
}

\author{
Marco Schade ${ }^{1,2,3}\left[\right.$ ] Jörg Ansorge ${ }^{1}$
}

Received: 10 November 2021 / Accepted: 30 December 2021 / Published online: 19 January 2022

(c) The Author(s) 2022

\begin{abstract}
Thyreophora is a clade of globally distributed herbivorous ornithischian dinosaurs. The earliest forms are known from the Early Jurassic, and their latest surviving representatives witnessed the end-Cretaceous mass extinction. Throughout their evolutionary history, these 'shield bearers' became lumbering quadrupeds, evolved a wide array of bony armor, plates and spikes, as well as sweeping tail weapons in the form of tail clubs and thagomizers. An isolated new thyreophoran osteoderm from a Lower Jurassic Konservatlagerstätte near Grimmen is described and, with the aid of micro-CT data, compared to an osteoderm of the early diverging thyreophoran Emausaurus ernsti from a different stratigraphic horizon at the same locality.
\end{abstract}

Keywords Dinosauria $\cdot$ Thyreophora $\cdot$ Toarcian $\cdot$ Early Jurassic $\cdot$ Germany

\section{Introduction}

Only a few dinosaur remains are known from the Lower Jurassic of Europe, including the Sinemurian Scelidosaurus harrisonii Owen 1859 from Dorset, England and Lusitanosaurus liasicus Lapparent and Zbyszewski 1957 of similar age from Portugal. Lower Toarcian fossils comprise $\mathrm{Ohm}$ denosaurus liasicus Wild 1978 from Ohmden near Holzmaden, South Germany, the fragment of a putative megalosaurian vertebra in an Ahrensburg drift boulder (von Huene 1966) and the remains of Emausaurus ernsti Haubold 1990 from Grimmen in northeastern Germany, and some potential gravisaurian sauropod bone fragments from the latter

Handling Editor: Hans-Dieter Sues.

Marco Schade

marco.schade@stud.uni-greifswald.de

Jörg Ansorge

ansorge@uni-greifswald.de

1 Institute of Geography and Geology, Palaeontology and Historical Geology, University of Greifswald, 17489 Greifswald, Germany

2 Zoological Institute and Museum, Cytology and Evolutionary Biology, University of Greifswald, 17489 Greifswald, Germany

3 Department of Earth and Environmental Sciences, Palaeontology and Geobiology, Ludwig-Maximilians-Univer sität, 80333 München, Germany locality (Stumpf et al. 2015). Here, we report an isolated thyreophoran osteoderm from Grimmen and compare it with osteoderms of Scelidosaurus and Emausaurus.

The clay pit near Grimmen (northeastern Germany) is well known for its rich assemblage of lower Toarcian marine and terrestrial fossils (e.g., Ernst 1967, 1991; Haubold 1990; Ansorge 1996, 2003, 2007; Stumpf et al. 2015; Stumpf 2016; Konwert and Stumpf 2017). The abandoned clay pit displays Upper Liassic sediments (Fig. 1), although badly accessible nowadays. The lower Toarcian "Green Series" clay was mined for the production of light expanded clay aggregate (LECA) until 1995. The clay deposit was dislocated and elevated by Pleistocene glacial advances from nearby source rocks on the top of the Grimmen anticline. In the result, the Jurassic clay is intercalated as a giant drift within Pleistocene tillites (Ernst 1991; J.A., pers. obs.). The clay itself is highly deformed, folded and fractured in a way that detailed lithological observations are difficult. The oldest sediments exposed are upper Pliensbachian sands. Following a hiatus, resulting from a sea-level low stand, the lower Toarcian (tenuicostatum zone) is built of about $1 \mathrm{~m}$ coarse- to finegrained sand of shallow-marine origin. Within the sand, a thin clay layer contains carbonate concretions with ammonites, indicating that this is part of the semicelatum subzone. On the sand follows a heterolithic sediment of about $0.60 \mathrm{~m}$ thickness, regarded as Posidonia shale equivalent by Ernst (1967). At the top of this unit, carbonate concretions occur from which the holotype of Emausaurus was prepared (Ernst 

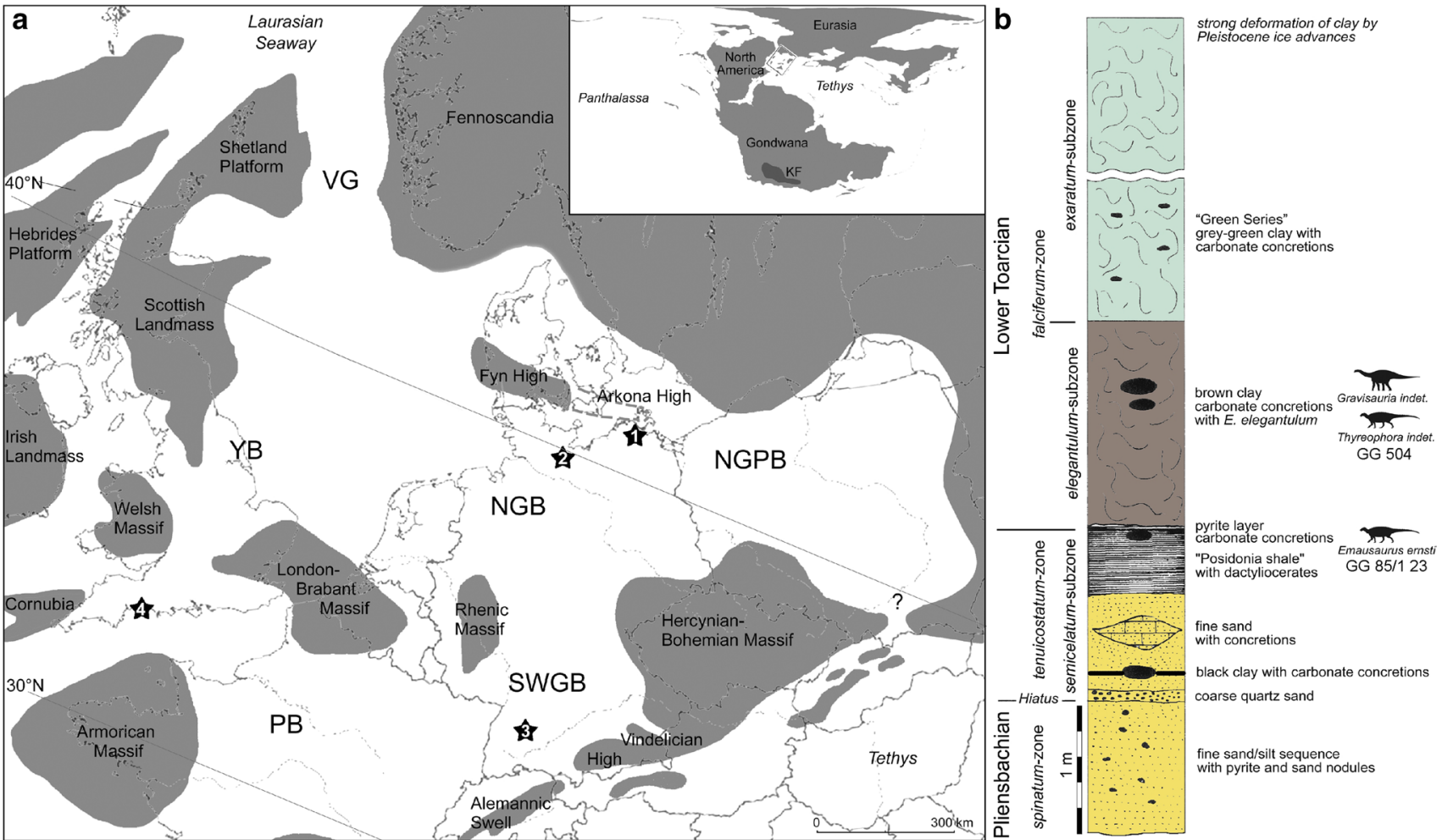

Fig. 1 a Lower Jurassic palaeogeography of central Europe with dinosaur find spots. 1. Grimmen, 2. Ahrensburg, 3. Ohmden, 4. Lyme Regis. $N G P B$ Northeast German Polish Basin, $N G B$ North German Basin, $S W G B$ South West German Basin, $P B$ Paris Basin, $Y B$ York-

1967, 1991; Haubold 1990). The Posidonia shale equivalent is overlain by a brown clay containing laminated carbonate concretions with the ammonite Eleganticeras elegantulum (elegantulum subzone of falciferum zone), drift wood, as well as the potential gravisaurian remains published by Stumpf et al. (2015), and the osteoderm described herein. A comparison of the mineralogical attributes of the bones indicate that the gravisaurian remains probably do not originate from the horizon with insect-bearing carbonate concretions of the "Green Series" clay of exaratum subzone, contradicting Stumpf et al. (2015). In addition to the terrestrial tetrapods, the presence of abundant insects (Ansorge 1996, 2003) and a single spider (Selden \& Dunlop 2014) indicates a rather short distance to the mainland or certain islands. A possible source might be the Arkona high (an island in the extension of the Ringköping-Fyn high to the southeast; Seidel 2019), rather than the more distal Scandinavian mainland. shire Basin, $V G$ Viking Graben; $\mathbf{b}$ schematic profile of the Grimmen section, modified after Ansorge 2007, with occurrences of dinosaur remains

\section{Institutional abbreviations}

BRSMG, Bristol City Museum and Gallery, Bristol, UK; GG, Greifswalder Geologische Sammlungen, University of Greifswald, Greifswald, Germany; MNA, Museum of Northern Arizona, Flagstaff, USA; YPM, Peabody Museum of Natural History, Yale University, New Haven, USA.

\section{Materials and methods}

J.A. found the broken pieces of the new thyreophoran osteoderm GG 504 in 2017 and subsequently prepared them. Fracture surfaces of the bone pieces were moistened with alcohol to enhance visibility of details for macro-photography. To reveal its inner structure, we scanned the osteoderm GG 85/1 23, belonging to the holotype of Emausaurus ernsti, using the micro-computed tomography device MicroXCT-200 housed in the Department of Cytology and Evolutionary Biology, University of Greifswald. Parameters-voltage: $60 \mathrm{kV}, \mathrm{X}$-ray tube current: $133 \mu \mathrm{A}$, exposure time: $5 \mathrm{~s}$, voxel size: $0,0,465,132 \mathrm{~mm}$. The figures showing CT data were produced utilizing the software Amira (6.1), 


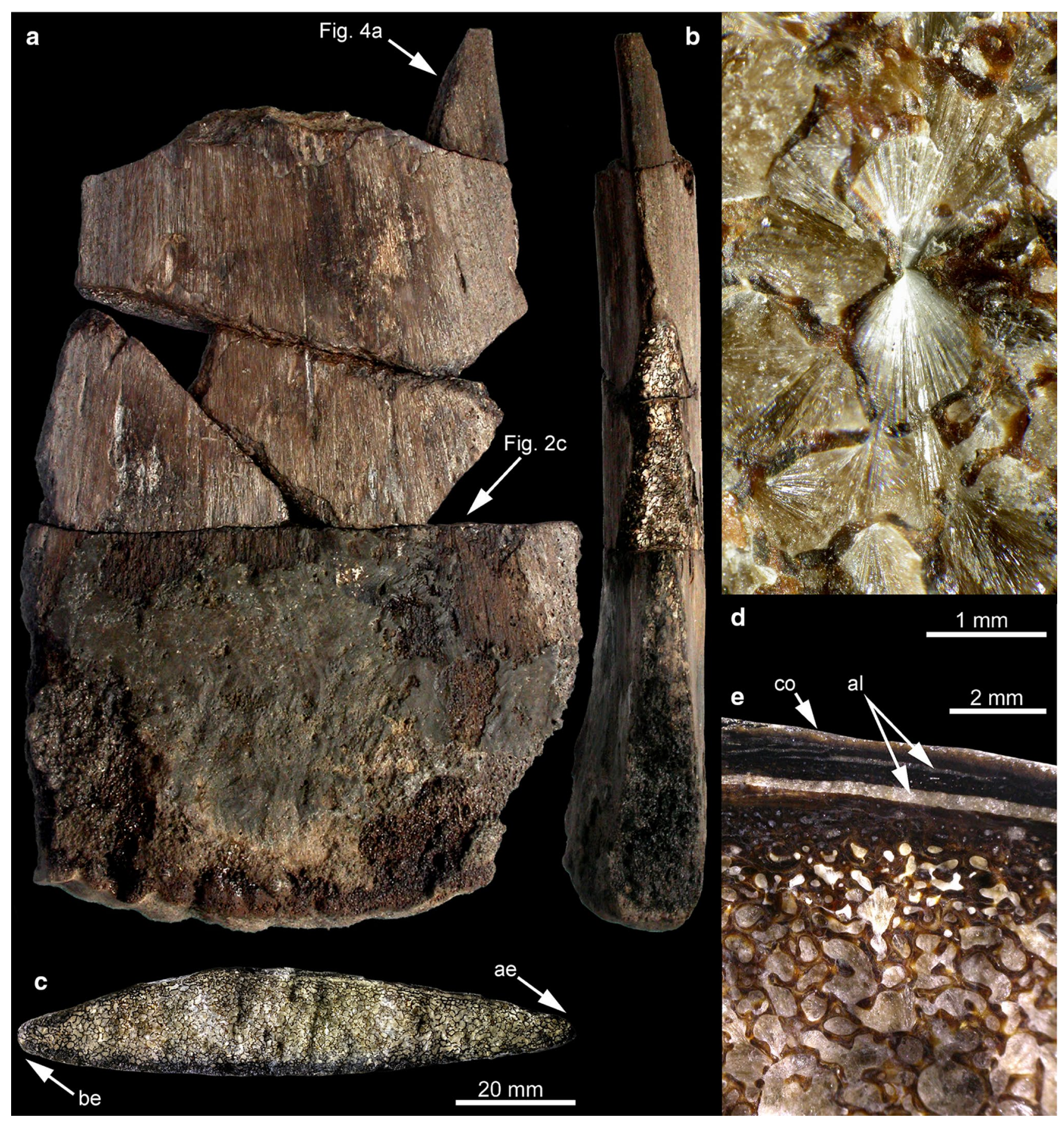

Fig. 2 GG 504, osteoderm of an unknown thyreophoran dinosaur. a top view of the slightly convex side; $\mathbf{b}$ view on the acute edge, showing the inclination of the osteoderm and its base towards the less convex side; c cross section of the proximodistal mid-length; $\mathbf{d}$ intertrabecular spaces filled with aragonite; e magnified part of a cross section. $a e$ acute edge, $a l$ aragonitic layers, $b e$ blunt edge, $c o$ cortex based on tiff files (16 bit). GG 504 and GG 85/1 23 are housed in the paleontological collection of the Institut für Geographie und Geologie in Greifswald, Germany.

\section{Description}

gen. et sp. indet. (GG 504) Figs. 2, 3, 4.

The partial osteoderm GG 504 consists of five matching fragments. Assembled, the specimen measures some $15.5 \mathrm{~cm}$ proximodistally (Figs. 2a, 3a); judging from the 


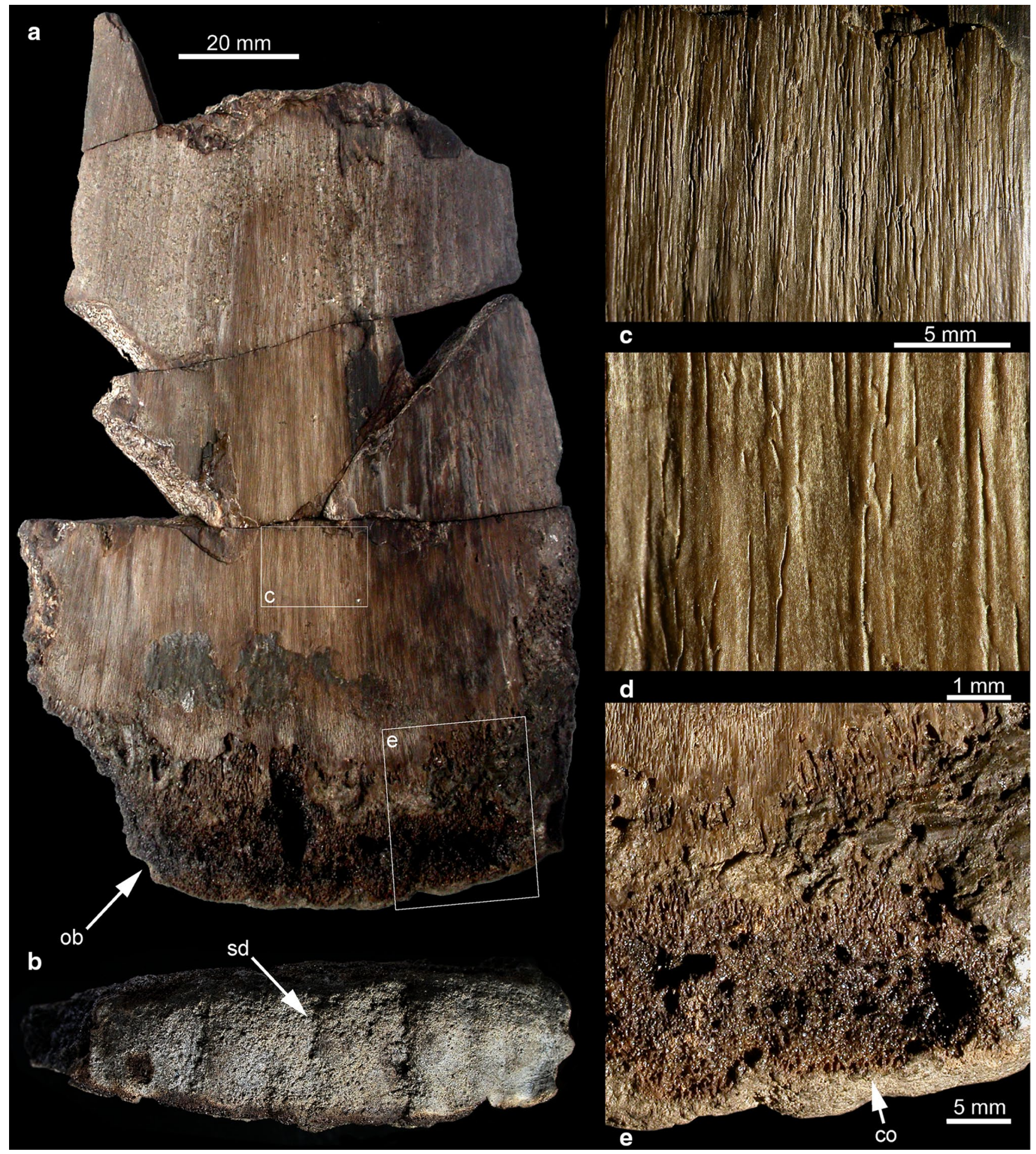

Fig. 3 GG 504, osteoderm of an unknown thyreophoran dinosaur. a top view of the pronounced convex side; $\mathbf{b}$ base in proximal view; $\mathbf{c}$ close-up of striated cortex shown in $\mathbf{a} ; \mathbf{d}$ magnified cortex; e close-up

slightly converging edges, maybe around one fourth of the original length is missing. Whereas both sides show a proximodistally oriented striation (appearing wrinkled under the microscope; Fig. 3a, c, d), the slightly of section close to the base shown in a. $c o$ cortex, $o b$ offset base, $s d$ slight depression

convex side possesses a more roughened and irregular surface proximally. The rugose base seems to have been slightly offset from the rest of the osteoderm. The base of the osteoderm is proximally slightly convex in top 


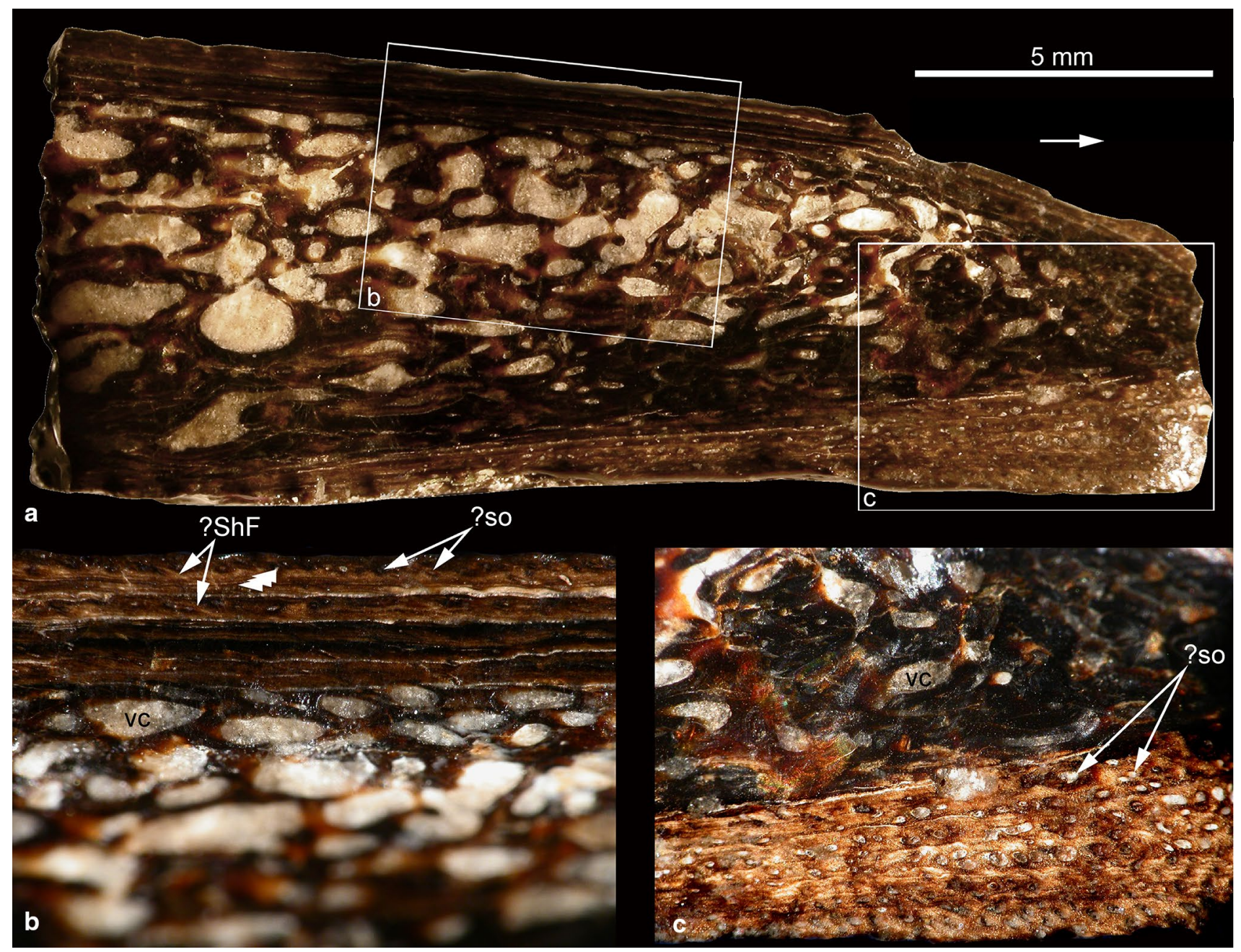

Fig. 4 GG 504, osteoderm of an unknown thyreophoran dinosaur. a magnified section of the distal-most fragment, arrow points towards former apex; $\mathbf{b}$ close-up of cortex from the pronounced convex side shown in a, arrows without lines hint towards potential LAGs; c

view. In proximal view, the base has shallow depressions that extend from one side to the other, and very small, irregularly placed vascular foramina seem to be visible (Fig. 3b). In the top view, the osteoderm is widest proximally between both edges and becomes narrower distally. Its proximal thickness measures some $2 \mathrm{~cm}$. The thickness gradually decreases distally and towards both edges, while the maximum thickness is not situated at the mid-width, producing an asymmetrical cross section (Fig. 2c). Furthermore, one side appears only slightly convex, whereas the other side is more pronounced convex. The whole osteoderm is slightly inclined or bent towards the less convex side; this is also perceivable on the base (Fig. 2b). The edges seem to have been sub-parallel proximally and gradually converged distally; however, the distal-most part of the osteoderm might have been rather blunt. In cross section, one edge is more acute than the other (Fig. 2c). close-up of cortex from the slightly convex side shown in a. ?ShF potential Sharpey's fibers, ?so potential secondary osteons, $v c$ vascular cavities

There is a thin and laminated cortex surrounding potential Haversian bone, which is transitioning to larger vascular cavities towards the core (Figs. 2c, e; 4); the latter two structures are made up by a network of trabeculae. Whereas the cortex of the slightly convex side tends to be thicker and more porous-in cross section-than of the pronounced convex side (although the surfaces of both seem to be intact), potential secondary osteons, lines of arrested growth (LAG) and low-angled Sharpey's fibers seem to be present on both sides (Figs. 2c; 4). Best seen in the laminated cortex of the clearly convex side, layers of the actual cortex are occasionally separated from each other by thin layers of aragonite (Figs. 2c, e; 4a, b). In some places, LAGs seem perceivable, but not to a degree that allows secure and continuous counting (Fig. 4b). The spaces created by the trabeculae (vascular cavities and/or erosion cavities; Scheyer and Sander 2004; Scheyer et al. 

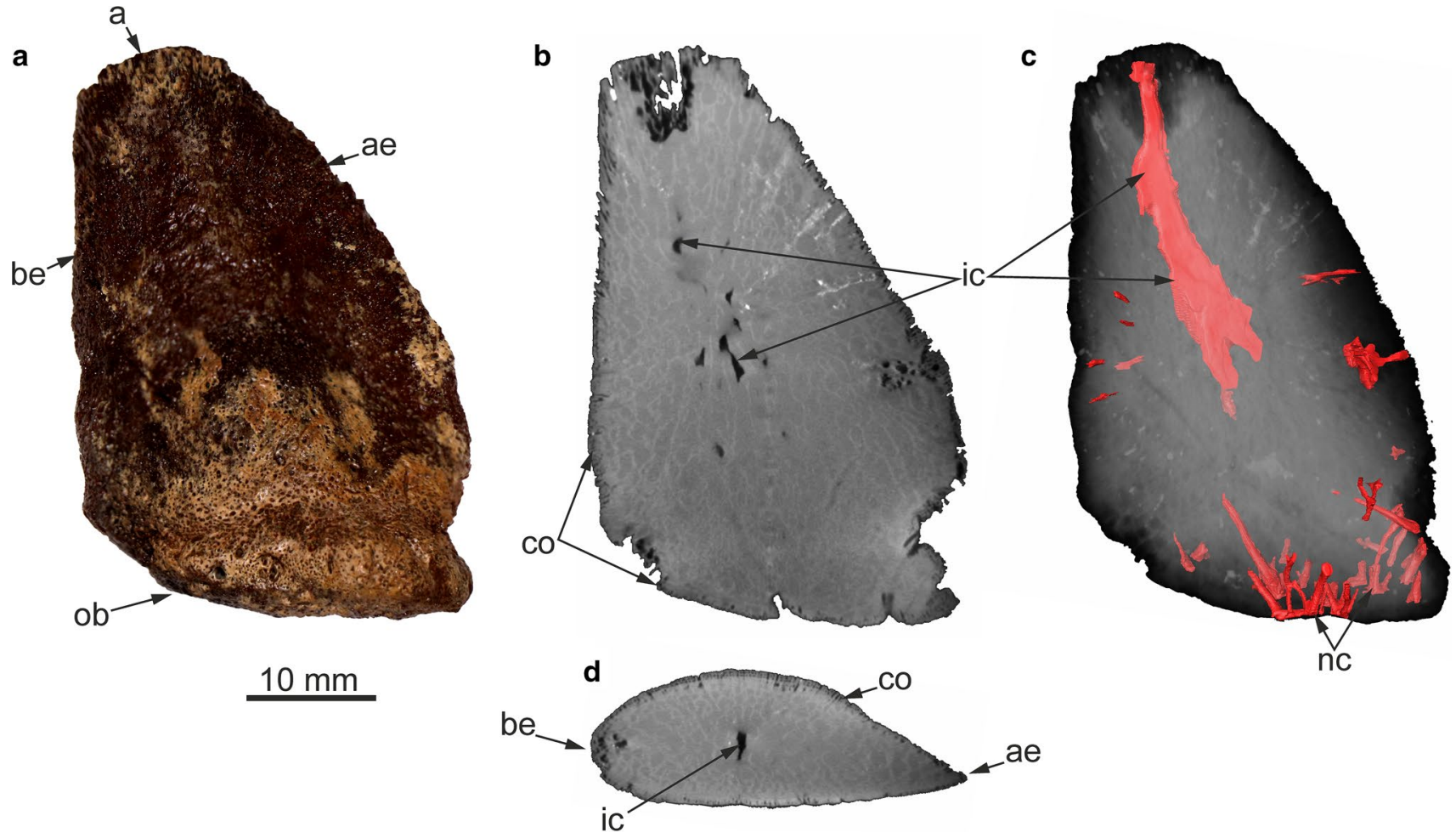

Fig. 5 a GG 85/1 23, osteoderm of the Emausaurus ernsti holotype; b sagittal(?) micro-CT slice close to the mid-width; c volume rendering with segmented vascular structures; $\mathbf{d}$ transverse(?) micro-CT slice close to the proximodistal mid-length. The convex side faces

2013) are filled with aragonitic crystals (Fig. 2d); they are largest close to the core of the osteoderm and become smaller distally in all directions. Furthermore, the cortex occupies more of the cross-sectional surface in relation to the cancellous bone toward the former apex of the osteoderm. Fractions close to the offset base suggest that GG 504 bears a thin basal cortex (Fig. 3e).

\section{Emausaurus ernsti Haubold, 1990 (GG 85/1 23), Fig. 5.}

The largest (around $4.5 \mathrm{~cm}$ proximodistally) and almost completely preserved osteoderm of Emausaurus, GG 85/1 23, resembles GG 504 in many aspects. However, the rugose base of GG 85/1 23 shows more and larger vascular foramina, is more clearly offset from the rest of the osteoderm, and the sides, still showing very slight striations in some places in Haubold (1990) and photographs prior to the latest preparation of 2013, appear rather porous nowadays. Furthermore, although the edges of GG 504 slightly converge, one edge of GG 85/1 23 is more or less straight and blunt, whereas the other edge is convex in outline, more acute, and gives the osteoderm a somewhat inclined appearance (Fig. 5a). The CT data of GG 85/1 23 suggest a thin cortex, also at the base (Fig. 5b, d). Additionally, canals from the towards the observer in a-c. $a$ apex, $a e$ acute edge, $b e$ blunt edge, co cortex, ic internal cavity with potential apical canal, $n c$ nutritive canals, $o b$ offset base

abundant foramina at the base of GG 85/1 23 could be traced to one fourth of the proximodistal length of the osteoderm (Fig. 5c). Furthermore, there are vascular canals on both sides and both edges as well. One large cavity with a respective canal seems to have reached between the proximodistal mid-length of the osteoderm and the eroded apex. However, whereas the distal-most extent of this canal might represent a preservational artifact, the trabecular network is clearly more wide spaced in the core of the osteoderm and shows increasingly smaller inter-trabecular spaces distally in all directions.

\section{Discussion}

Although GG 85/1 23 is almost completely preserved and certainly represents an osteoderm, the isolated and incomplete nature of GG 504 may open up the possibility that it is not an osteoderm. Some long bones, like those of dinosaurs, can be very wide on the epiphyses and very narrow on the diaphysis. Furthermore, the proximal aspect of GG 504 shows shallow depressions, which resemble the epiphysis of some long bones; however, osteoderm bases seem to be variable in thyreophorans, being longitudinally concave as in some osteoderms of Scutellosaurus lawleri 
(MNA.V.175; Breeden et al. 2021), funnel-like concave as in some osteoderms of Emausaurus (Haubold 1990), or convex as is the case in GG 85/1 23. Additionally, GG 504 has prominently striated sides and - for a long bone-sharp edges, as well as an exceptionally thin (between the sides) and wide (between the edges) cross section in relation to the base. Also, the thin and somewhat elongate nature of GG 504 may resemble a broken neural spine or transverse process. In both cases, the putative base of GG 504 would then represent the somewhat thickened and roughened distal end of such a neural arch projection. Across the vertebral column in many taxa, transverse processes and neural spines can change their appearance considerably, e.g. in respect to their general morphology, orientation, thickness, lamination (e.g., Wilson 1999; Evers et al. 2015); and obviously, there is a lot of interspecific variation as well. The asymmetrical morphology (differently convex sides, inclination to one side, differently developed cortex) of GG 504 seems to exclude a sagittal position as neural spine. Furthermore, GG 504 would be much wider anteroposteriorly distally than it would be proximally, which is rather not typical for neural spines. Also, neural spines often show irregular textures on their anterior and posterior edges; such features are absent in GG 504. Considering transverse processes, often they show sub-parallel anterior and posterior edges, are dorsoventrally thickened because of the centrodiapophyseal laminae (sensu lato) and the diapophysis is rather sub-circular (and not elongated oval like the putative base of GG 504). The-from one side to the other-thin shape, as well as the slightly converging and relatively sharp edges, and again, the width relation between the putative base and distal portion of GG 504 make it unlikely to represent a transverse process. However, since long bones, neural spines and transverse processes (as well as the rest of their skeleton) are very diverse across Mesozoic terrestrial and marine reptiles (e.g., Sues 2019), these options cannot be excluded with absolute certainty.

Still, the specimens GG 504 and GG 85/1 23 most probably represent a comparably elongated and flat type of osteoderm. In addition to thyreophorans, other archosauriforms can bear dermal armor as well, but are unlikely to represent the owner of GG 504 and GG 85/1 23, based on morphological and/or geological age (e.g., Scheyer and Sander 2004; Curry Rogers et al. 2011; Desojo et al. 2013).

Following most phylogenetic analyses (e.g., Thompson et al. 2012; Raven \& Maidment 2017), Scutellosaurus (Early Jurassic, USA), Emausaurus and Scelidosaurus (Early Jurassic, UK) represent early diverging thyreophorans, and are sister taxa to Eurypoda (which comprise Ankylosauria and Stegosauria; but see Norman 2020c). Although there is no consensus of what exactly is smooth or rugose, it seems that, within Ankylosauria, ankylosaurids (partly club-tailed) and nodosaurids (spike-shouldered) possess rather rugose surfaces on their osteoderms (e.g., Scheyer and Sander 2004;
Hayashi et al. 2010), whereas early diverging thyreophoran osteoderms can show rugose and smooth surfaces (Norman, 2020b). Scheyer and Sander (2004: fig. 12) reported a relatively thin cortex in Scelidosaurus. Furthermore, they mention that osteoderms of Scutellosaurus are similar to what is known about the external and internal characteristics of Scelidosaurus osteoderms. Early diverging thyreophoran and ankylosaurid osteoderms share a basal cortex, which is absent in nodosaurids (Scheyer and Sander 2004; Main et al. 2005; Hayashi et al. 2010).

The pattern of numerous independent vascular canals in GG 85/1 23 differs from the condition found in a dorsal plate of Stegosaurus (specimen YPM 57,716) in that no 'main channel' is present from which other vascular canals branch off (Farlow et al. 2010). However, both osteoderms resemble each other in the restriction of the largest vascular canals to a relatively proximal part of the osteoderm (Farlow et al. 2010). Furthermore, osteoderms situated in the neck region of early diverging thyreophorans, stegosaurs, and ankylosaurs can be somewhat similar in appearance (e.g., Chengkai et al. 2007; Maidment et al. 2015; Brown 2017; Norman 2020b). Hence, because of the geological setting (no ankylosaur or stegosaur is known from Lower Jurassic deposits) they were found in, their overall morphology and their detailed characteristics (smooth surface with striations, thin cortex, basal cortex), early diverging thyreophoran affinities for GG 504 and GG 85/1 23 are assumed and, respectively, supported herein.

Concerning the former anatomical position and orientation of GG 504 and GG 85/1 23, it is worth noting that neither was found in articulation and that GG 504 is incompletely preserved. Norman (2020b) pointed out that the osteoderms of the early diverging thyreophoran Scelidosaurus vary considerably with respect to their position on the body and ontogeny. The usual overall arrangement of ankylosaur osteoderms constitutes a streamlined pattern with most osteoderms being posteriorly inclined (contrasted by protruding spike-like osteoderms on the neck and shoulders of the nodosaurid Edmontonia longiceps (e.g., Brown et al. 2017). Furthermore, osteoderms similar to the elongated and flat type as GG 504 and GG 85/1 23 are, at least in some taxa, flat to slightly convex dorsally and clearly convex ventrally, which can be observed on the fully articulated neck and shoulder region of the nodosaurid Borealopelta markmitchelli (Brown 2017). Hence, there may be two details helpful to orient an isolated osteoderm: inclination (anterior/posterior), and the convexity or concavity of both sides (dorsal/ventral). The acuteness of both edges seems to be no reliable proxy for an anterior or posterior direction (M.S., pers. obs. on osteoderms of Emausaurus). In comparison to the specimen BRSMG LEGL 0004 of Scelidosaurus, GG 504 might match the morphology of a large osteoderm on the lateral neck base with slightly converging edges (Norman 
2020b: figs. 8, 22). Hence, GG 504 is herein interpreted as representing a lateral osteoderm of the neck or shoulder region of an early diverging thyreophoran. If this assignment is correct, GG 504 possibly belongs to an individual much larger than the juvenile Scelidosaurus specimen BRSMG LEGL 0004 and Emausaurus.

Haubold (1990) interpreted GG 85/1 23 as a right parasagittal osteoderm. However, it seems that osteoderms can be more variable morphologically, the more anterior they are situated (Brown 2017). Whereas ankylosaurids tend to possess bulkier and less protruding osteoderms (e.g., Arbour and Currie 2013), a comparable shape to GG 85/1 23 is found in osteoderms of the neck and shoulder region of nodosaurids (e.g., Brown 2017) and-more importantlythe head, neck and shoulder region of Scelidosaurus (Norman 2020a, b). In fact, the occipital osteoderms of the latter (BRSMG LEGL 0004) are strikingly similar in outline, and the 'waisted zone' between the porous base and the distal osteoderm (Norman 2020a: fig. 16; b: figs. 18, 19). However, the lateral edges of the occipital osteoderms are slightly laterally curved in Scelidosaurus, whereas the respective edge of GG 85/1 23 is straight. Additionally, it is not clear if the dorsal and ventral sides of the occipital osteoderms in Scelidosaurus are concave, straight or convex, and if the medial and lateral edges are similarly developed as in GG $85 / 123$ in respect to their acuteness. The fossae where the occipital osteoderms attach to the posterodorsal aspects of the supraoccipital, opisthotic, parietal and squamosal in Scelidosaurus make up $65 \%$ of the mediolateral skull width (Norman 2020a). Based on the reconstruction of Haubold (1990), this width would be $70 \%$ in Emausaurus. Hence, the likely socio-sexual component of keratinous sheaths on thyreophoran osteoderms (which are similar to cranial horns of extant bovids because of their external structure in bearing a relatively smooth surface with slight grooves or striations, and small foramina, which hint towards having been nutritive for the potentially keratinous caps, e.g., Main et al. 2005; Farlow et al. 2010; Brown et al. 2017; Brown 2017; Norman 2020a, b) may render the holotype of Emausaurus a sub-adult and not a juvenile.

Acknowledgements We thank Marie Hörnig, Steffen Harzsch, Ingelore Hinz-Schallreuter and Stefan Meng (all University of Greifswald, Germany) for their help and support. M.S. was supported with the Bogislaw scholarship, funded by the University of Greifswald. We also thank Hans-Dieter Sues and Benjamin Breeden for very helpful comments, which improved an earlier version of this manuscript, as well as Mike Reich for editorial handling of this article.

Author contributions MS designed the project and segmented the CT data. JA unearthed GG 504 and prepared the specimen. MS and JA prepared the figures, interpreted the data and wrote the manuscript.

Funding Open Access funding enabled and organized by Projekt DEAL.

\section{Declarations}

Conflict of interests The authors declare no competing interests.

Open Access This article is licensed under a Creative Commons Attribution 4.0 International License, which permits use, sharing, adaptation, distribution and reproduction in any medium or format, as long as you give appropriate credit to the original author(s) and the source, provide a link to the Creative Commons licence, and indicate if changes were made. The images or other third party material in this article are included in the article's Creative Commons licence, unless indicated otherwise in a credit line to the material. If material is not included in the article's Creative Commons licence and your intended use is not permitted by statutory regulation or exceeds the permitted use, you will need to obtain permission directly from the copyright holder. To view a copy of this licence, visit http://creativecommons.org/licenses/by/4.0/.

\section{References}

Ansorge, J. 1996. Insekten aus dem oberen Lias von Grimmen (Vorpommern, Norddeutschland). Neue Paläontologische Abhandlungen 2: 1-132.

Ansorge, J. 2003. Insects from the Lower Toarcian of Middle Europe and England. Proceedings of the Second Palaeoentomological Congress, Kraków 2001. Acta Zoologica Cracoviensia 46 (Suppl. Fossil Insects): $291-310$.

Ansorge, J. 2007. Lower Jurassic clay pit of Klein Lehmhagen near Grimmen. In Geo-Pomerania Excursion guide, eds. R.-O. Niedermeyer, R. Dobracki, and K. Schütze. Biuletyn Państwowego Instytutu Geologicznego 424: 37-41.

Arbour, V.M., and P.J. Currie. 2013. Euoplocephalus tutus and the diversity of ankylosaurid dinosaurs in the Late Cretaceous of Alberta, Canada, and Montana, USA. PLoS ONE 8 (5): e62421. https://doi.org/10.1371/journal.pone.0062421.

Breeden, B.T., III., T.J. Raven, R.J. Butler, T.B. Rowe, and S.C.R. Maidment. 2021. The anatomy and palaeobiology of the early armoured dinosaur Scutellosaurus lawleri (Ornithischia: Thyreophora) from the Kayenta Formation (Lower Jurassic) of Arizona. Royal Society Open Science 8: 201676. https://doi.org/10.1098/ rsos. 201676

Brown, C.M., D.M. Henderson, J. Vinther, I. Fletcher, A. Sistiaga, J. Herrera, and R.E. Summons. 2017. An exceptionally preserved three-dimensional armored dinosaur reveals insights into coloration and Cretaceous predator-prey dynamics. Current Biology. https://doi.org/10.1016/j.cub.2017.06.071.

Brown, C.M. 2017. An exceptionally preserved armored dinosaur reveals the morphology and allometry of osteoderms and their horny epidermal coverings. PeerJ 5 e4066. https://doi.org/10. 7717/peerj.4066.

Chengkai, J., C.A. Foster, X. Xing, and J.M. Clark. 2007. The first stegosaur (Dinosauria, Ornithischia) from the Upper Jurassic Shishugou formation of Xinjiang, China. Acta Geologica Sinica (english Edition) 81: 351-356.

de Lapparent, A.F., and G. Zbyszewski. 1957. Les dinosauriens du Portugal Mémoires Des Services Géologiques Du Portugal. Nouvelle Série 2: 1-63.

Desojo, J.B., A.B. Heckert, J.W. Martz, W.G. Parker, R.R. Schoch, B.J. Small, and T. Sulej. 2013. Aetosauria: a clade of armoured pseudosuchians from the Late Triassic continental beds. In Anatomy, phylogeny and palaeobiology of early archosaurs and their kin, eds. S.J. Nesbitt, J.B. Desojo, and R.B. Irmis. Geological Society, London, Special Publications 389: 203-239. 
Ernst, W. 1967. Die Liastongrube Grimmen. Sediment Makrofauna Und Stratigraphie. Ein Überblick. Geologie 16: 550-569.

Ernst, W. 1991. Der Lias im Ton-Tagebau bei Grimmen (Vorpommern). Fundgrube 27: 171-183.

Evers, S.W., O.W.M. Rauhut, A.C. Milner, B.McFeeters, and R. Allain. 2015. A reappraisal of the morphology and systematic position of the theropod dinosaur Sigilmassasaurus from the "middle" Cretaceous of Morocco. PeerJ 3:e1323; https://doi.org/10.7717/ peerj.1323.

Farlow, J.O., S. Hayashi, and G.J. Tattersall. 2010. Internal vascularity of the dermal plates of Stegosaurus (Ornithischia, Thyreophora). Swiss Journal of Geosciences 103: 173-185. https://doi.org/10. 1007/s00015-010-0021-5.

Haubold, H. 1990. Ein neuer Dinosaurier (Ornithischia, Thyreophora) aus dem unteren Jura des Nördlichen Mitteleuropa. Revue de Paléobiologie 9: 149-177.

Hayashi, S., K. Carpenter, T.M. Scheyer, M. Watabe, and D. Suzuki. 2010. Function and evolution of ankylosaur dermal armor. Acta Palaeontologica Polonica 55 (2): 213-228.

Konwert, M., and S. Stumpf. 2017. Exceptionally preserved Leptolepidae (Actinopterygii, Teleostei) from the late Early Jurassic FossilLagerstätten of Grimmen and Dobbertin (Mecklenburg-Western Pomerania, Germany). Zootaxa 4243 (2): 249-296. https://doi. org/10.11646/zootaxa.4243.2.2.

Maidment, S.C, C. Brassey, P.M. Barrett. 2015. The postcranial skeleton of an exceptionally complete individual of the plated dinosaur Stegosaurus stenops (Dinosauria: Thyreophora) from the Upper Jurassic Morrison Formation of Wyoming, U.S.A. PLoS One 10(10):e0138352. https://doi.org/10.1371/journal.pone.0138352.

Main, R., A. De Ricqlès, J. Horner, and K. Padian. 2005. The evolution and function of thyreophoran dinosaur scutes: implications for plate function in stegosaurs. Paleobiology 31 (2): 291-314. https://doi.org/10.1666/0094-8373(2005)031[0291:TEAFOT] 2.0.CO;2.

Norman, D.B. 2020a. Scelidosaurus harrisonii from the Early Jurassic of Dorset, England: the dermal skeleton. Zoological Journal of the Linnean Society 190 (1): 1-53. https://doi.org/10.1093/zooli nnean/zlz085.

Norman, D.B. 2020a. Scelidosaurus harrisonii from the Early Jurassic of Dorset, England: cranial anatomy. Zoological Journal of the Linnean Society 188(1): 1-81. https://doi.org/10.1093/zooli nnean/zlz074.

Norman, D.B. 2020c. Scelidosaurus harrisonii (Dinosauria: Ornithischia) from the Early Jurassic of Dorset, England: biology and phylogenetic relationships. Zoological Journal of the Linnean Society 191(1): 1-86. https://doi.org/10.1093/zoolinnean/zlaa061.

Owen, R. 1859. Palaeontology. In Encyclopaedia Britannica, 8th edn. Edinburgh: Adam \& Charles Black, 91-176.
Raven, T.J., and S.C.R. Maidment. 2017. A new phylogeny of Stegosauria (Dinosauria: Ornithischia). Palaeontology 60: 401-408.

Rogers, K.C., M. D’Emic, R. Rogers, M. Vickaryous, and A. Cagan. 2011. Sauropod dinosaur osteoderms from the Late Cretaceous of Madagascar. Nature Communications 2 (1): 564. https://doi.org/ 10.1038/ncomms 1578 .

Scheyer, T.M., and P.M. Sander. 2004. Histology of ankylosaur osteoderms: implications for systematics and function. Journal of Vertebrate Paleontology 24: 874-893.

Scheyer, T.M., J.B. Desojo, and I.A. Cerda. 2013. Bone histology of phytosaur, aetosaur, and other archosauriform osteoderms (Eureptilia, Archosauromorpha). The Anatomical Record 297: 240-260.

Seidel, E. 2019. The Tectonic Evolution of the German offshore area, as part of the Trans-European Suture Zone (North and East of Rügen Island). PhD thesis, University of Greifswald. https://epub. ub.uni-greifswald.de/frontdoor/index/index/year/2019/docId/ 3033.

Selden, P.A., and J.A. Dunlop. 2014. The first fossil spider (Araneae: Palpimanoidea) from the Lower Jurassic (Grimmen, Germany). Zootaxa 3894 (1): 161-168. https://doi.org/10.11646/zootaxa. 3894.1.13.

Stumpf, S. 2016. New information on the marine reptile fauna from the lower Toarcian (Early Jurassic) "Green Series" of North-Eastern Germany. Neues Jahrbuch Für Geologie Und Paläontologie, Abhandlungen 280 (1): 87-105.

Stumpf, S., J. Ansorge, and W. Krempien. 2015. Gravisaurian sauropod remains from the marine late Early Jurassic (Lower Toarcian) of North-Eastern Germany. Geobios 48 (3): 271-279. https://doi.org/ 10.1016/j.geobios.2015.04.001.

Sues, H.D. 2019. The rise of reptiles: 320 million years of evolution. Baltimore: Johns Hopkins University Press.

Thompson, R.S., J.C. Parish, S.C.R. Maidment, and P.M. Barrett. 2012. Phylogeny of the ankylosaurian dinosaurs (Ornithischia: Thyreophora). Journal of Systematic Palaeontology 10 (2): 301-312.

von Huene, F. 1966. Ein Megalosauriden-Wirbel des Lias aus norddeutschem Geschiebe. Neues Jahrbuch Für Geologie Und Paläontologie, Monatshefte 1966 (1): 318-319.

Wild, R. 1978. Ein Sauropoden-Rest (Reptilia, Saurischia) aus dem Posidonienschiefer (Lias, Toarcium) von Holzmaden. Stuttgarter Beiträge zur Naturkunde. Serie B (geologie Und Paläontologie) 41: 1-15.

Wilson, J.A. 1999. A nomenclature for vertebral laminae in sauropods and other saurischian di- nosaurs. Journal of Vertebrate Paleontology 19: 639-653. https://doi.org/10.1080/02724634.1999. 10011178 